REVISTA

\title{
PÃO DE FORMA ENRIQUECIDO COM FARINHA DE DOURADO (Coryphaena hippurus): UMA ALTERNATIVA PARA O INCREMENTO DE CONSUMO DE PESCADO SOB A FORMA PROCESSADA
}

\author{
ENRICHED FORM BREAD WITH FISH MEAL (Coryphaena hippurus): AN \\ ALTERNATIVE TO THE FISH CONSUMPTION INCREASE IN THE FORM \\ PROCESSED
}

\author{
Dayvison Mendes Moreira ${ }^{1 *}$ \\ Marcelo Giordani Minozzo 2 \\ Dayse Aline Silva Bartolomeu de Oliveira ${ }^{3}$ \\ Monique Lopes Ribeiro ${ }^{4}$ \\ Flávia Regina Spago de Camargo Gonçalves ${ }^{5}$

\begin{abstract}
${ }^{1}$ Instituto Federal do Espírito Santo - Campus Píuma. E-mail:dayvison.engpesca@gmail.com ${ }^{2}$ Instituto Federal do Espírito Santo - Campus Píuma. E-mail:marcelogm@ifes.edu.br ${ }^{3}$ Instituto Federal do Espírito Santo - Campus Píuma. E-mail:dayse.oliveira@gmail.com ${ }^{4}$ Instituto Federal do Espírito Santo - Campus Píuma. E-mail:monique.ribeiro@ @ifes.edu.br ${ }^{5}$ Instituto Federal do Espírito Santo - Campus Píuma. E-mail:flavia.goncalves@ifes.edu.br *Autor para correspondência: dayvison.engpesca@gmail.com
\end{abstract}

Artigo submetido em 19/06/2019, aceito em 24/09/2019 e publicado em 23/12/2019.

Resumo: O pescado constitui fonte de proteínas, vitaminas e minerais de alto valor biológico, essenciais para nutrição humana. Estas características tornam a farinha de peixe uma excelente matéria-prima, capaz de suprir as necessidades nutricionais e gustativas de um alimento. Este trabalho teve como objetivo elaborar pães de forma enriquecidos com farinha de dourado (Coryphaena hippurus) para aumentar a qualidade e valor nutricional do produto, avaliando os perfis sensorial, microbiológico e físico-químico. Para obtenção da polpa de dourado, a matéria-prima foi submetida a um processo de lavagem, seguido de secagem. Foram desenvolvidas três formulações com diferentes percentuais de farinha de dourado $(0,7,5$ e $15 \%)$, em substituição à farinha de trigo. Os pães foram avaliados através de análises sensorial (teste de escala hedônica e perfil de atributos), para perfil microbiológico (Staphylococcus aureus, Salmonella sp. e Coliformes totais e termotolerantes) e análise físico-quimicamente (composição centesimal). O teste de perfil de atributos mostrou que o pão enriquecido com $7,5 \%$ de farinha de dourado só diferiu significativamente do pão com $15 \%$ para atributo de odor avaliado. Todos os pães apresentaram aceitação superior a 58\%. Os pães com 7,5 e $15 \%$ de farinha de dourado apresentaram um aumento no conteúdo proteico, lipídico e cinzas em relação ao conteúdo proteico do pão padrão, Todas as formulações atenderam aos padrões microbiológicos da legislação vigente.

Palavras-chave: pão; farinha de peixe; proteína animal.

Abstract: The fish are sources of protein, vitamins and minerals of high biological essential value for human nutrition. These features make fishmeal an excellent raw material, able to meet the nutritional 
needs and taste of a food. This study aimed to elaborate breads enriched with mahi mahi (Coryphaena hippurus) to increase the quality and nutritional value of the product, evaluating the sensory, microbiological and physico-chemical profiles. To achieve the fish meal, the raw material is subjected to a washing process, followed by drying. Three formulations were developed with different fishmeal percentages $(0,7.5$ and $15 \%)$, replacing the wheat flour. The breads were evaluated sensory (hedonic scale test and attribute profile), to the microbiological (Staphylococcus aureus, Salmonella sp.and coliforms) and physic chemical (centesimal composition). The attribute profile bread test showed that only $7.5 \%$ differed significantly with $15 \%$ bread evaluated for odor attribute. All breads showed higher acceptance of 58\%. Breads with 7.5 and $15 \%$ fish meal showed an increase in protein, lipid and ash content in relation to the protein content of standard bread. All formulations met the microbiological standards of current legislation.

Keywords: bread; fish meal; animal protein.

\section{INTRODUÇÃO}

Os consumidores procuram alimentos mais saudáveis de forma a suprir suas necessidades nutricionais e gustativas. O pescado constitui fontes de proteínas de alto valor biológico, com um perfil de aminoácidos essenciais para nutrição humana, além de conter vitaminas e minerais fundamentais para alimentação humana. Com a elaboração de pães de forma enriquecidos com farinha de dourado (Coryphaena hippurus), aumentamos a qualidade e valor nutricional de um dos alimentos mais antigos e consumidos por grande parte da população, oferecendo desta forma produtos mais saudáveis, podendo atingir consumidores de diversos níveis econômicos e sua aceitação pode ser maior devido à ausência de espinhos, facilitando o consumo por crianças e idosos, aumentando desta maneira o consumo da carne do pescado sob a forma processada. O pão é um produto bem popular no Brasil devido ao excelente sabor, preço e disponibilidade, com consumo per capita de $27 \mathrm{~kg}$ por ano, podendo ser consumido como lanche ou até mesmo junto com as refeições (AZEVEDO et al., 2011).

O enriquecimento do pão com farinha de dourado oferece um aumento considerável do seu conteúdo proteico devido a seu enriquecimento com proteínas, cálcio, fósforo, ferro, e especialmente o ácido graxo ômega3, além de satisfação nutricional e sabor diferenciado, traz benefícios à saúde. Uma pequena quantidade dessa farinha é o suficiente para atender a demanda do organismo humano.

$\mathrm{O}$ alto valor nutricional encontrado em sua composição agrega valor ao produto bem como incentiva a um desenvolvimento sustentável. Esses componentes se destacam pela importância nutricional, fisiológica e metabólica, que atuam diretamente no processo de crescimento e desenvolvimento do ser humano (GODOY et al., 2010).

Os pães estão presentes nas diferentes classes sociais devido ao sabor, preço e disponibilidade (ESTELLER, 2004) e vem sendo objeto de muitos estudos de enriquecimento (ILYAS, et al.,1996).

Diferentes métodos com o alimento processado vêm sendo empregado desde a metade do século XX, fortificando os alimentos com nutrientes de forma a ser aceita pelo consumidor, com objetivos de reforçar o valor nutritivo e prevenir ou corrigir deficiências de um ou mais nutrientes (REILLY, C.,1996; BRASIL, 1998).

A indústria de processamento de pescado, devido à falta de conhecimento de processos tecnológicos para a produção de novos produtos, acumula grandes quantidades de subprodutos, os quais apresentam um alto potencial para a fabricação de produtos nutritivos a serem oferecidos a baixo custo e que possam ser consumidos pela população de baixa renda e carente de alimentos saudáveis (PESSATTI, 2004). 
Com o desenvolvimento deste estudo espera-se incrementar o consumo de pescado na forma de produtos processados, aumentando assim novas alternativas para os consumidores adquirirem outras formas deste produto que não seja a tradicional enlatada. Este trabalho tem como objetivo elaborar pães de forma enriquecidos com farinha de dourado (Coryphaena hippurus) para aumentar a qualidade e valor nutricional do produto, avaliando os perfis sensorial, microbiológico e físico-químico.

\section{MATERIAIS E MÉTODOS}

A matéria prima consistiu em filés de dourado (Coryphaena hippurus). Os filés foram obtidos congelados de uma indústria pesqueira local, na cidade de Piúma-ES, e transportados para o laboratório de Processamento de Pescados do Instituto Federal do Espírito Santo - IFES Campus Piúma, sendo armazenada em freezer com temperatura de aproximadamente $-20^{\circ} \mathrm{C}$.

\subsection{ELABORAÇÃO DA POLPA DE PESCADO}

Os filés foram descongelados em temperatura de resfriamento $\left(-7^{\circ} \mathrm{C}\right)$ por aproximadamente 30 minutos. Após o descongelamento da matéria prima os filés foram cortados em cubos com aproximadamente $4 \mathrm{~cm}$ de largura e colocados em um multiprocessador de alimentos por 5 minutos até obter consistência pastosa.

Após o processamento, a pasta homogeinizada foi submetida a três etapas de lavagem e prensadas ao final de cada etapa em peneira de alumínio com malha de $0,85 \mathrm{~mm}$. Esta etapa de lavagem tem como objetivo a retirada das proteínas sarcoplasmáticas, concentrando as proteínas miofibrilares, após o processo de lavagem a poupa de pescado foi dividida em duas partes e colocadas sobre duas bandejas de metais higienizados e acomodadas uniformemente formando uma fina camada até ser submetidos à secagem em estufa com circulação forçada de ar, a $60^{\circ} \mathrm{C}$, por aproximadamente 7 horas. Após a secagem o produto foi triturado e peneirado sobre uma malha de $0,85 \mathrm{~mm}$ de acordo com a metodologia descrita por Centenaro et al. (2007), conforme podemos observar o processo na Figura 1.

Figura 1: Processo de obtenção da farinha de dourado

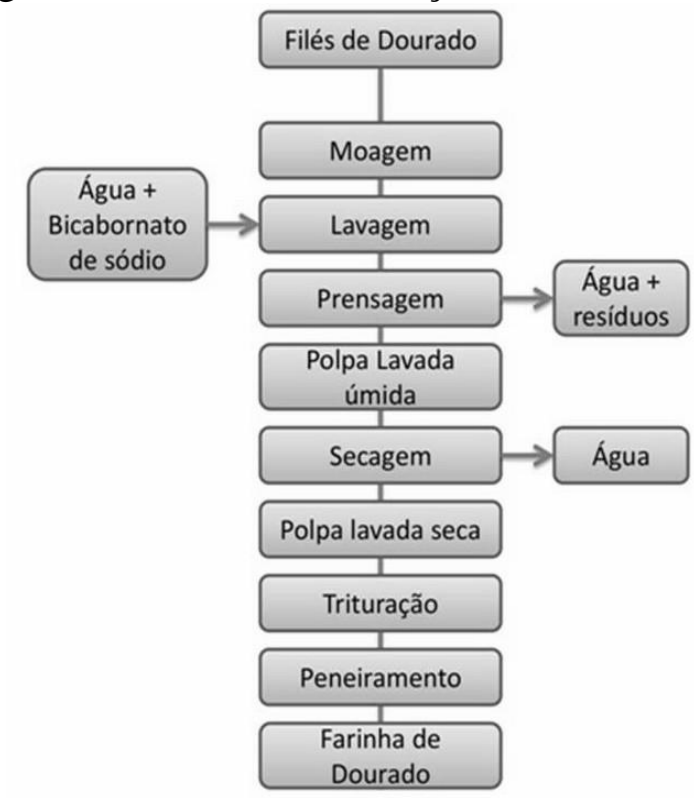


Fonte: Autor (2018)

\subsection{FORMULAÇÃO E ELABORAÇÃO DOS PÃES}

Foram elaboradas três formulações de pães de forma enriquecidas com farinha de dourado: 742 (0\%), 351 (7,5\%) e 869 (15\%), em substituição à farinha de trigo. $\mathrm{Na}$ Tabela 1, encontram-se os ingredientes e as formulações propostas para $\mathrm{o}$ experimento.

Para elaboração dos pães de forma, os ingredientes foram pesados e misturados os ovos, açúcar, sal, óleo e homogeneizados por 2 minutos em liquidificador industrial. Foi acrescentado o fermento e leite morno à $30^{\circ} \mathrm{C}$, e homogeneizados por mais 2 minutos. Após a homogeneização dos ingredientes, a massa líquida foi acomodada em bacia plástica onde foi acrescentada as farinhas e homogeneizada utilizando uma colher até obter uma consistência homogênea. A massa foi distribuída em uma estufa à $28^{\circ} \mathrm{C}$ por 45 minutos para o processo da $1^{a}$ fermentação, em seguida, a massa foi retirada e misturada por 1 minuto e levada novamente à estufa por 30 minutos para $2^{\mathrm{a}}$ fermentação. Após, a $2^{\mathrm{a}}$ fermentação as formulações foram colocadas em forma untada com óleo e levadas a estufa até dobrar de tamanho completando o processo da $3^{\text {a }}$ fermentação, processo aproximado entre 35 minutos. Logo após as formulações foram levadas para assar em forno a gás entre $180-200^{\circ} \mathrm{C}$, durante 15 minutos.

Tabela 1: Formulação dos pães de forma expressa em porcentagem.

\begin{tabular}{lccc}
\hline \multicolumn{1}{c}{ Ingredientes } & 742 & 351 & 869 \\
\hline Farinha de trigo & $100 \%$ & $92,5 \%$ & $85 \%$ \\
\hline Farinha de peixe & $0 \%$ & $7,5 \%$ & $15 \%$ \\
\hline Açúcar & $7,5 \%$ & $7,5 \%$ & $7,5 \%$ \\
\hline Sal & $2,5 \%$ & $2,5 \%$ & $2,5 \%$ \\
\hline Óleo & $5,0 \%$ & $5,0 \%$ & $5,0 \%$ \\
\hline Fermento biológico & $3,75 \%$ & $3,75 \%$ & $3,75 \%$ \\
\hline Leite & $60 \%$ & $60 \%$ & $60 \%$ \\
\hline Ovos inteiros & $21,25 \%$ & $21,25 \%$ & $21,25 \%$ \\
\hline
\end{tabular}

Fonte: Autor (2018)

\subsection{AVALIAÇÃO FÍSICO-QUÍMICA}

As análises físico-químicas dos pães foram realizadas no Laboratório de Química, do Instituto Federal do Espírito Santo - Campus Piúma. As determinações da análise de composição centesimal, do pão de forma foram realizadas em todas as formulações em triplicata.

\subsection{UMIDADE}

Foi utilizado o método adaptado 950.46 da AOAC (2000), dessecação a $105^{\circ} \mathrm{C}$. A amostra foi pesada em um cadinho e levado a estufa a $105^{\circ} \mathrm{C}$ por 3 horas e depois esfriado no dessecador e pesado em balança analítica. 


\subsection{CINZAS}

Determinação da cinza segundo o método adaptado n. 920.153 (AOAC, 2000), foi realizada por incineração em mufla a $550^{\circ} \mathrm{C}$. O princípio deste método diz que as cinzas são obtidas por ignição de quantidade conhecida de amostra em cadinho previamente tarado e mantido em mufla a $550^{\circ} \mathrm{C}$ até eliminação completa do carvão, ou seja, até o resíduo obter uma coloração branca ou cinza esbranquiçada. $\mathrm{O}$ Cadinho com amostra foi levado a mufla por 1 hora a $550^{\circ} \mathrm{C}$ e depois esfriada em dessecador, a amostra foi pesada em balança analítica e levada novamente a mufla por mais 1 hora até ficar com a coloração esbranquiçada.

\subsection{LIPÍDIOS}

Foi utilizado pelo extrator de Soxhlet método n. 960.39 (AOAC, 2000), que se fundamenta na solubilidade dos lipídios em solvente (éter de petróleo). Sistema de extração de gordura por préextração por imersão.

\subsection{PROTEÍNA}

Foi utilizado o método de Kjeldahl método n. 940525 (AOAC, 2000), que se baseia na transformação do nitrogênio da amostra em sulfato de amônio através da digestão com ácido sulfúrico (p.a.) e posterior destilação com liberação da amônia, que é fixada em solução ácida e titulada, utilizando o fator de transformação do nitrogênio em proteína de 6,25 , segundo AOAC, 94025 (2000).

\subsection{ATIVIDADE DE ÁGUA $\left(\mathrm{A}_{\mathrm{W}}\right)$}

Utilizou-se o método 978.18 (AOAC, 2000) equipamento AquaLab 4TEV com temperatura da amostra $18,0^{\circ} \mathrm{C}$ $( \pm 1)$. A atividade de água $\left(\mathrm{a}_{\mathrm{w}}\right)$ é um dos fatores intrínsecos dos alimentos e é uma medida qualitativa que possibilita avaliar a disponibilidade de água livre que é suscetível a diversas reações.

\subsection{AVALIAÇÃO MICROBIOLÓGICA}

A investigação dos microorganismos foi realizada no Laboratório de Ecologia microbiana do Instituto Federal do Espírito Santo- Campus Piúma. Foram realizadas avaliações microbiológicas em triplicata no produto final de acordo com a metodologia recomendada por SILVA et al. (2010).

Procedeu-se a separação asséptica de porções das amostras, totalizando $25 \mathrm{~g}$ de amostra, adicionou $225 \mathrm{ml}$ de solução salina $(0,85 \%)$ peptonada $(0,1 \%)$ e levou para um homogeinizador de amostras por 60 segundos. Obtendo-se o homogenato, (diluição $10^{-1}$ ), para fazer as outras análises, adaptado por (SILVA, 1997; A.O.A.C, 2000).

\subsection{PESQUISA DE SALMONELLA}

Incubou-se a amostra homogeneizada a $35^{\circ} \mathrm{C}$ por 24 horas para fazer um pré-enriquecimento. No enriquecimento transferiu-se $1 \mathrm{~mL}$ da amostra pre-enriquecida para o caldo selenito cistina e $0,1 \mathrm{ml}$ para o caldo Rappaport Vassiliadis. Incubou-se a $35^{\circ} \mathrm{c}$ por 24 horas o caldo selenito cistina e o caldo Rappaport Vassiliadis foi incubado a $42^{\circ} \mathrm{C}$ por 24 horas. Com o auxílio de uma alça de platina estriou-se a amostra enriquecida nas placas de petri contendo ágar XLD (xylose lysine deoxycholate) e verde brilhante, e foi incubada na estufa a $35^{\circ} \mathrm{C}$ por 24 horas. Após 24 horas foram selecionados as colônias típicas de salmonela e foram realizados testes bioquímicos para a confirmação das mesmas. Para os testes bioquímicos foram usados os seguintes meios de cultura: citrato de Simmons agar, TSI agar (triple sugar iron), agar LIA (lisina iron ágar), caldo lisina descarboxilase e fenilalanina, adaptado de (A.O.A.C., 2000). 


\subsection{STAPHYLOCOCUS COAGULASE POSITIVA}

Em placas de Petri estéreis contendo aproximadamente $15 \mathrm{~mL}$ do meio Agar Baird Parker com emulsão de gema de ovo telurito de potássio, foram semeados $0,1 \mathrm{~mL}$ das diluições $10^{-1}$ previamente preparadas. Com o auxílio de alça de drigalski o inóculo foi espalhado cuidadosamente por toda a superfície do meio. A seguir, as placas foram incubadas em estufa à temperatura de $35^{\circ} \mathrm{C}$ por 48 horas e após esse período contou-se as colônias típicas de estafilococos (SILVA, 1997).

\subsection{COLIFORMES A $45^{\circ} \mathrm{C}$}

Para contagem dos coliformes termotolerantes a $45^{\circ} \mathrm{C}$ foi utilizado à técnica dos tubos múltiplos. Transferiu-se a amostra homogeneizada para 15 tubos contendo $10 \mathrm{~mL}$ de caldo lactosado. Para 5 tubos foram transferidos $10 \mathrm{~mL}$ de amostra, outros 5 tubos foram transferidos $1 \mathrm{~mL}$ de amostra e para os outros 5 tubos restantes foram transferidos $0,1 \mathrm{~mL}$ da amostra. Os tubos foram incubados por 48 horas a $35^{\circ} \mathrm{C}$. Após o período de incubação, com o auxílio de uma alça de platina passou-se uma alíquota dos tubos lactosados que apresentaram formação de gás para tubos contendo $10 \mathrm{~mL}$ de caldo EC (Escherichia coli). Incubou-se na estufa a $45^{\circ} \mathrm{C}$ por 24 horas e observou se houve formação de gás em algum tubo (SILVA, 1997).

\subsection{AVALIAÇÃO SENSORIAL}

A avaliação sensorial dos pães foi realizada mediante o uso do teste de escala hedônica de 9 pontos, e teste de perfil de atributos, sendo eles, aroma, sabor, textura, aparência e cor, utilizando-se um teste afetivo que indica o quanto gostou ou desgostou de cada formulação preparada segundo ABNT (1993); IAL (2008).

Participaram 50 julgadores no Ifes/Piúma. Todos julgadores eram consumidores diários de pão, com idade de 15 a 50 anos, de ambos os sexos, escolhidos de modo aleatório, sem conhecimento sobre a composição das amostras. Os resultados dos testes foram avaliados por meio da análise de variância univariada (ANOVA), conduzida para os resultados das avaliações para determinar significância e efeitos principais entre amostras e julgadores, seguido do teste de Tukey HDS $(\alpha=0,05)$ (MONTGOMERY, 2002).

Antes de iniciar os testes, os julgadores receberam orientação do método e procedimento das avaliações. Em todos os testes, foi oferecida água à temperatura ambiente para todos os julgadores com o intuito de enxaguarem e promover a limpeza das papilas gustativas.

Para avaliar o perfil sensorial das amostras aplicou-se o teste de perfil de atributos, avaliando; aparência, cor, odor, sabor, e textura, e solicitou-se que a degustação das amostras fosse feita avaliando cada amostra em relação aos atributos especificados na ficha, utilizando uma escala numérica, onde 1 representa péssimo e 5 excelente. Para o perfil de atributos a análise de dados foi feita através de comparação dos valores obtidos em cada atributo, para cada amostra analisadas. As médias obtidas representados em gráfico aranha, para mostrar as diferentes similaridades (TEIXEIRA, 1987).

A aceitabilidade dos pães de forma foi avaliada, utilizando o teste de aceitação, que indica o quanto gostou ou desgostou de cada formulação preparada utilizando escala hedônica estruturada de nove pontos, segundo a ABNT (1993).

A análise estatística dos resultados foi feita, utilizando análise de variância (ANOVA) e cálculo das médias por Tukey. Foram consideradas como tratamentos as três formulações de pães de forma, 
avaliadas por 50 julgadores no Instituto Federal do Espírito Santo - campus Piúma.

\section{RESULTADOS E DISCUSSÃO}

\section{RENDIMENTO DAS POLPAS ÚMIDA E SECA}

A Tabela 2 mostra os valores de rendimento das etapas do processo de obtenção da polpa seca em relação ao filé inteiro. Os resultados obtidos com os cálculos de rendimento mostraram que a polpa seca, apresentou um rendimento de $8 \%$ em relação ao filé inicial, considerado baixo quando comparado ao rendimento da polpa úmida e do filé moído, esse resultado foi maior ao demonstrado por Centenaro (2007) na elaboração de polpa seca de cabrinha, tal diferença pode se dar devido as partes da matéria prima utilizada, a cabrinha possui aproximadamente um terço de sua estrutura formada pela cabeça, o que diminui o rendimento em todas as etapas da obtenção da polpa. O baixo rendimento da polpa seca, comparadas com o filé úmido inteiro, também se deve a perdas durante algumas operações do processo.
Tabela 2: Rendimento das etapas do processo de obtenção da polpa de dourado

\begin{tabular}{|c|c|}
\hline Porção & $\begin{array}{l}\text { Rendimento } \\
\text { (g. } 100 \mathrm{~g}^{-1} \text { ) }\end{array}$ \\
\hline Pescado inteiro & 100 \\
\hline Filé moído & 100 \\
\hline Polpa lavada úmida & 62,5 \\
\hline Polpa lavada seca & 8,0 \\
\hline
\end{tabular}

A Tabela 3 mostra a composição centesimal das formulações de pães de forma enriquecidos com farinha de dourado. Conforme a Tabela 3 , os valores encontrados para umidade são próximos aos encontrados por Anton (2006) onde comparou as analise físico química de pães comuns e integrais, obtendo uma média entre as formulações de $35 \%$ de umidade. Sendo diferentes dos encontrados por Gaio e Scopel (2014) na elaboração de pães de milho com farinha de tilápia encontraram uma média de 28.7 de umidade nas formulações. Diferenças essas podendo ser explicadas devido ao processo de cocção no forno.

Tabela 3: Composição centesimal do pão

\begin{tabular}{cccccc}
\hline & Umidade(\%) & Cinza(\%) & Lipídios(\%) & Protídeos(\%) & $\begin{array}{c}\text { Atividade de } \\
\text { Água }\end{array}$ \\
\hline 742 & 41,0 & 1,6 & 4,5 & 8,3 & 0.959 \\
351 & 39,6 & 1,79 & 4,6 & 20,5 & 0.958 \\
869 & 41,0 & 2,08 & 4,8 & 23,7 & 0.960 \\
\hline
\end{tabular}

Fonte: Próprio autor

Pode-se observar que os resultados encontrados pelos pesquisadores Noleto et al. (2017), foram menores para cinzas dos encontrados neste estudo, isto pode ser explicado devido as diferenças de porcentagem de farinha de pescado utilizadas na formulações desenvolvidas. Porém o aumento das cinzas com acréscimo de farinha de dourado foi semelhantes ao de Reis (2013) na elaboração de macarrão com farinha de polpa de tilápia.

O teor de lipídios aumentou com adição de farinha de dourado. Esse resultado corrobora ao obtido por Abreu, et al. (2012) para estudos de bolacha adicionada de farinha de peixe, ocorrendo um aumento 
para lipídios com o aumento do nível de farinha de peixe.

Os valores de proteína aumentaram de acordo com o aumento do nível de farinha dourado, resultados também encontrados por Gaio e Scopel (2014) na elaboração de pães de milho com farinha de tilápia, utilizando diferentes concentrações farinha a partir da carcaça da tilápia. O teor proteico era o componente desejado para ser incorporado ao pão, que obteve uma boa variação. Observou-se um aumento protéico nos pães adicionados farinha de dourado 351 e 869 comparado a formulação padrão 742.

Para atividade de água o resultado encontrado é semelhante aos resultados de Follmann e Centenaro (2013) onde desenvolveram um bolo de laranja adicionada farinha de tilápia. As formulações dos pães não tiveram grandes diferenças entre si, se mantendo próximo nos valores de atividade de água.

\section{AVALIAÇÃO MICROBIOLÓGICA}

Os resultados das análises sugerem que os pães atendem a legislação vigente quanto aos padrões microbiológicos aceitos. Indicaram, por consequência, que a matériaprima e o preparo dos produtos foram realizados em condições sanitárias adequadas.
Nos alimentos, os micro-organismos utilizam seus nutrientes para perpetuação de sua espécie e consequentemente provocam sua deterioração. Alguns podem representar risco à saúde do homem e outros animais e estão relacionados a condições precárias de higiene durante a produção e armazenamento.

De acordo com a RDC $\mathrm{n}^{\mathrm{o}} 12$ (ANVISA, 2000), os limites estabelecidos para pescado in natura são: para Staphylococcus coagulase positiva no máximo $10^{3} \mathrm{UFC} / \mathrm{g}$ e para Salmonella $s p$. ausência em $25 \mathrm{~g}$. Já, para pães, o máximo permitido para coliformes a $45^{\circ} \mathrm{C}$ é de $10^{2}$ UFC e Salmonella sp. ausência em $25 \mathrm{~g}$.

Os resultados das análises microbiológicas, como pode ser observado na Tabela 4, evidenciam que a pesquisa de Staphylococcus coagulase positiva e Salmonella sp. nos pães analisados estão em conformidade com legislação vigente, indicando que a matéria prima e o preparo foram processados e realizados em condições sanitárias adequadas, ou seja, estavam aptos para o consumo, este resultado também foi encontrado por Leitão e Favacho (2014), avaliando farinha de tambaqui para elaboração de pães, torradas e bolachas.

Tabela 4: Caracterização microbiológica do pão de forma

\begin{tabular}{cccc}
\hline & $\begin{array}{c}\text { Coliformes a 45 } \\
(\mathbf{U F C} / \mathbf{g})\end{array}$ & $\begin{array}{c}\text { Salmonella sp em } \\
\mathbf{2 5 g}\end{array}$ & $\begin{array}{c}\text { Staphylococcus aureus } \\
\text { coagulase positiva } \\
\text { (UFC/g) }\end{array}$ \\
\hline 742 & $1 \mathrm{X} 10^{2}$ & Ausência & $<100$ \\
351 & $1,2 \mathrm{X} 10^{2}$ & Ausência & $<100$ \\
869 & $1,4 \mathrm{X} 10^{2}$ & Ausência & $<100$ \\
\hline
\end{tabular}

Fonte: Autor (2018)

Tendo em vista que os resultados observados para esses micro-organismos foram baixos, pode-se concluir que não afetaram a qualidade do produto final. Para a produção e manipulação de alimentos é necessário que se aplique as Boas Práticas de Fabricação (BPF), que se baseia no princípio de que se cada etapa do processo for controlada o produto final terá qualidade assegurada e evitará a ocorrência de doenças provocadas pelo consumo de alimentos contaminados. 


\section{AVALIAÇÃO SENSORIAL}

A partir do teste abaixo, verificou-se que não houve diferença significativa na aceitação global para os pães acrescidos de farinha de dourado (TABELA 5), resultado semelhante ao de Tavares et al. (2010) utilizando farinha de matrinxã na elaboração de pães de forma, onde a formulação com substituição de $7,5 \%$ da farinha de trigo, foi a melhor avaliada pelos provadores em todos os parâmetros sensoriais, com melhor aceitação do que a formulação padrão. A formulação com maior concentração de farinha de dourado $15 \%$ apresentou diferença significativa quanto ao atributo do odor, resultado este semelhante ao descrito por Centenaro et al. (2007) na utilização da cabrinha para elaboração de pães. A formulação 351 não diferiu significativamente da formulação 869 para os atributos aparência, cor, sabor e textura, e nem em sua aceitação global, resultado semelhante ao de Fukishinha et al. (2012) utilizando farinha com resíduos de tilápia na elaboração de pães, onde os resultados dos pães com $5 \%$ e $15 \%$ de farinha tiveram melhor aceitação do que os pães com $10 \%$ de farinha de tilápia. Foi observado que com aumento da farinha de dourado nas formulações a massa final ficava mais pesada com menor crescimento, indicando que uma concentração maior que $15 \%$ de farinha de dourado na formulação levasse a um resultado insatisfatório na textura devido as altas concentrações de ácidos graxos.

Os pães foram submetidos ao teste da escala hedônica de 9 pontos para avaliar a aceitação dos 50 julgadores, conforme Figura 2.

Através dos dados obtidos na análise sensorial pode-se dizer que a farinha de dourado apresenta propriedades que podem substituir, em partes, a farinha de trigo de pães de forma sem alterar negativamente suas características sensoriais, podendo substituir em até $7,5 \%$ do total da farinha de trigo usada para a fabricação de pães de forma, acima desse percentual, características como o odor podem ser afetadas.

Tabela 5: Avaliação sensorial dos atributos e aceitação global

\begin{tabular}{cccc}
\hline Atributos & $\mathbf{7 4 2}$ & $\mathbf{3 5 1}$ & $\mathbf{8 6 9}$ \\
\hline Aparência & $3,96^{\mathrm{a}}$ & $3,86^{\mathrm{a}}$ & $3,90^{\mathrm{a}}$ \\
cor & $4,00^{\mathrm{a}}$ & $3,94^{\mathrm{a}}$ & $3,86^{\mathrm{a}}$ \\
odor & $3,88^{\mathrm{a}}$ & $3,44^{\mathrm{a}}$ & $3,06^{\mathrm{b}}$ \\
Sabor & $3,62^{\mathrm{a}}$ & $3,44^{\mathrm{a}}$ & $3,28^{\mathrm{a}}$ \\
Textura & $3,78^{\mathrm{a}}$ & $3,76^{\mathrm{a}}$ & $3,48^{\mathrm{a}}$ \\
Aceitação Global & $6,4^{\mathrm{a}}$ & $5,8^{\mathrm{a}}$ & $5,8^{\mathrm{a}}$ \\
\hline
\end{tabular}

*Letras iguais indicam que não há diferença significativa entre as médias pelo teste de Tukey $(\mathrm{p}<0,05)$. Fonte: Autor (2018) 
Figura 2: Frequência das respostas do teste de aceitação

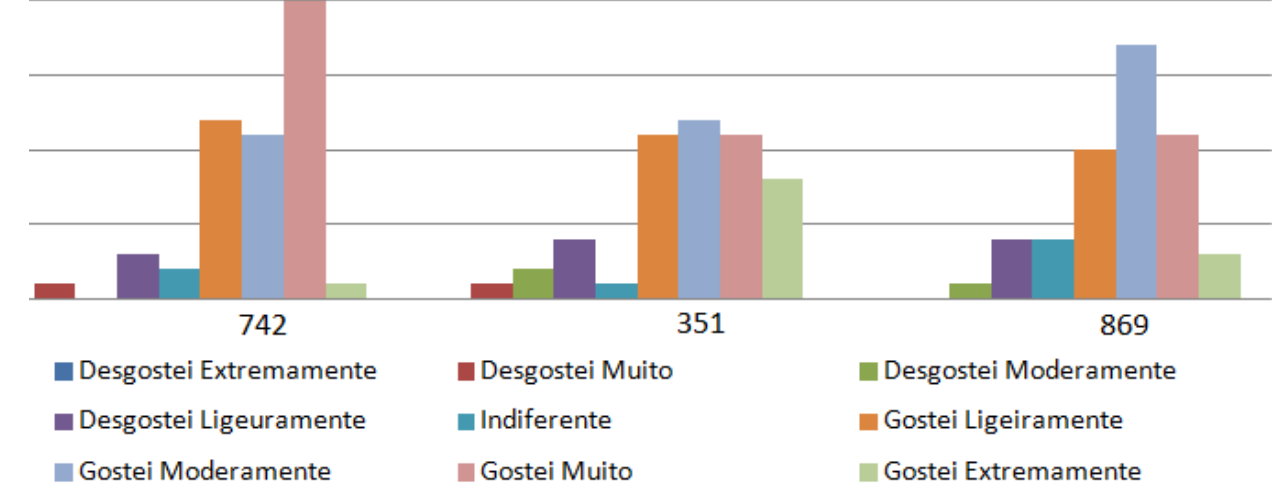

Fonte: Autor (2018)

A maioria dos julgadores "gostou moderadamente" das três amostras avaliadas e nenhum "desgostou extremamente". A formulação 742 de pão obteve o maior número de respostas para "gostei muito" (40\%) e maior índice de aceitabilidade $(64 \%)$. As outras amostras não tiveram diferença no índice de aceitabilidade. A amostra 869 apresentou maior número de respostas para "gostei moderadamente" (34\%) e a amostra 351 resultou no maior valor para "gostei extremamente" (16\%). Os pães também foram submetidos a realização do teste de perfil de atributos (FIGURA 3).

A formulação 869 apresentou uma diferença significativa da formulação 742 que concluíram que uma adição de $10 \%$ ou mais de CPP alterou a textura dos pães tornando a massa grosseira e compacta com maior odor característico de pescado.

Para o índice de aceitabilidade foi realizado o somatório das três maiores notas da escala hedônica $(7,8$ e 9). As formulações acrescentadas farinha de dourado 742 e 869 não tiveram diferença entre si em sua aceitabilidade com um total de $58 \%$

Figura 3: Gráfico aranha dos atributos avaliados dos pães

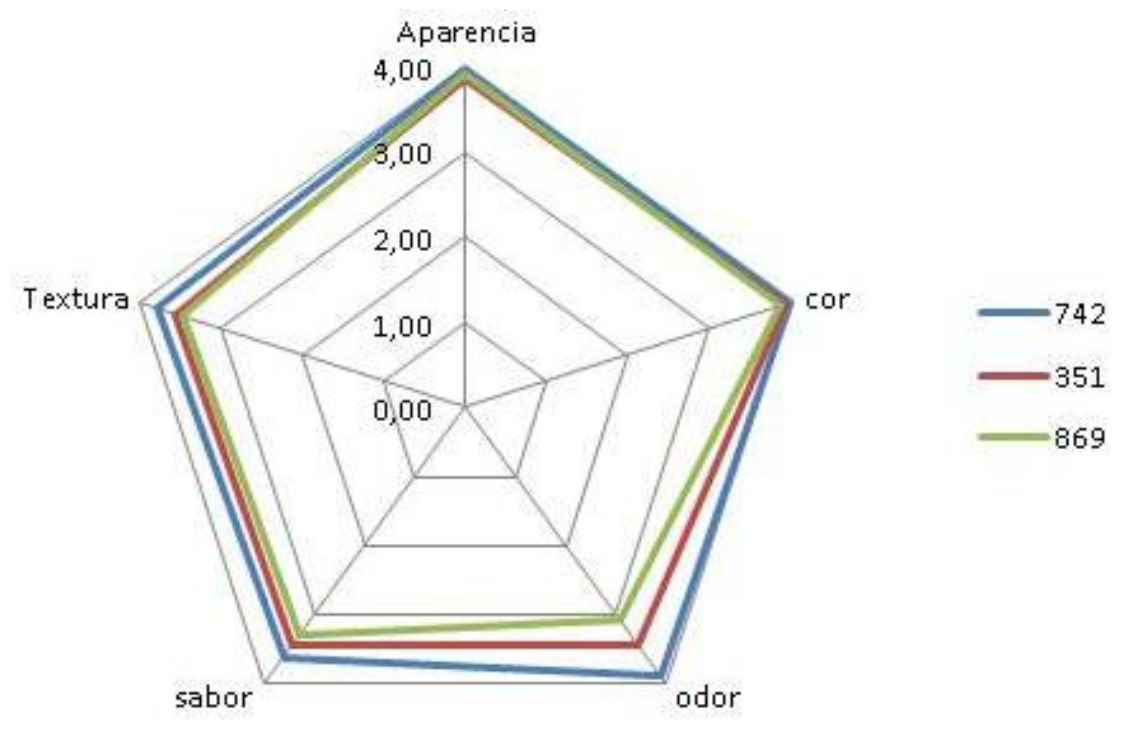

Fonte: Autor (2018) 


\section{CONCLUSÕES}

O presente trabalho teve como objetivo a elaborações de pães de forma enriquecidos com farinha de dourado. Os pães elaborados encontram-se em condições higiênicas satisfatórias. $\mathrm{O}$ rendimento da farinha de dourado foi de $8 \%$. Nos testes de aceitação global em Piúma-ES, as formulações não apresentaram diferença significativa.

A avaliação sensorial apresentou resultados diferentes no atributo do odor na formulação 869 (15\%). Com o índice de aceitabilidade a formulação $351(7,5 \%)$ se torna-se mais viável para elaboração de pães de forma enriquecidos com farinha de dourado. Houve um aumento considerável do conteúdo proteico, visando uma alternativa de consumo de pescado sob a forma processada. Dessa maneira, nas condições experimentais realizadas, pode-se concluir que a adição de polpa de pescado em pães pode contribuir para o enriquecimento proteico de produtos de panificação.

\section{REFERÊNCIAS}

ABREU, Bruno B.; FRANCO, Maria Luiza R. S.; GASPARINO, Eliane, VIEIRA, Vivian. Composição química, análise microbiológica e sensorial de bolachas enriquecidas com farinha de peixe. III Simpósio de Gestão do Agronegócio e III Mostra de Trabalhos Científicos, 2012.

AOAC.ASSOCIATION OF OFFICIAL ANALYTICAL CHENISTS.In Official Methods of Analysis (17th ed.). Gaithersburg, Maryland. Chapter 39, 2000.

ASSOCIAÇÃO BRASILEIRA DAS INDÚSTRIAS DE MASSAS ALIMENTÍCIAS.<http://www.abima.com. br/eam formatos.html>

ASSOCIAÇÃO BRASILEIRA DE NORMAS TÉCNICAS - ABNT. Análise sensorial dos alimentos $\mathrm{e}$ bebidas: terminologia. $1993.8 \mathrm{p}$.
AZEVEDO, Fátima L. A. A.; SILVA, Anna D. F.; MACIEL, Janeeyre F.; MOREIRA, Ricardo T.; FARIAS, Larissa R. G. Avaliação sensorial de pão de forma elaborado com soro de leite em pó. Revista Brasileira de Produtos Agroindustriais, Campina Grande, v. 13, n. 1, p.37-47, 2011

.BRASIL. Portaria n.31, de 13 de janeiro de 1998. Regulamento Técnico para Fixação de Identidade e Qualidade de Alimentos Adicionados de Nutrientes Essenciais. Diário Oficial da União,

CENTENARO, G. S., FEDDERN, V., BONOW, ELIZA, T., SALASMELLADO, M. Enriquecimento de pão com proteínas de pescado. Ciência Tecnologia de Alimentos, v.27, n.3, p.663-668, 2007. . ESTELLER, M.S. Fabricação de pães com reduzido teor calórico e modificações reológicas ocorridas durante o armazenamento. São Paulo, 2004, 248 p. Dissertação (mestrado em Tecnologia de Alimentos), Faculdade de Ciências Farmacêuticas, Universidade de São Paulo (USP).

FOLLMANN, Adriana M. C., CENTENARO, Andressa I. Elaboração de bolo de laranja com diferentes concentrações de farinha de carcaça de tilápia do Nilo (Oreochromis niloticus). Trabalho de conclusão de curso. 59 p. 2013. Universidade Tecnológica Federal do Paraná - Campus Medianeira - Paraná.

GAIO, C. SCOPEL, T. Elaboração de pão de milho com diferentes concentrações de farinha de carcaça de tilápia do Nilo. Mediana, 2014.

GODOY, L. C. DE et al. Análise sensorial de caldos e canjas elaborados com farinha de carcaças de peixe defumadas: aplicação na merenda escolar. Ciência e Tecnologia de Alimentos, v. 30, p. 86-89, maio 2010.IAL. Instituto Adolfo Lutz. Métodos Físico-Químicos para Análise de Alimentos /coordenadores Odair Zenebon, Neus SadoccoPascuet e Paulo Tiglea -- São Paulo: Instituto Adolfo Lutz, p. 1020. 2008.ILYAS, M. et al.The effect of iron fortification on the quality offortified 
bread.SarhadJournalofAgricultural, v. 12, n. 2,1996.

LEITÃO, B.R.G.S; FAVACHO,M.C. Elaboração e avaliação nutricional da farinha de pele do tambaqui ( Colossoma Macropomum) e utilização em produtos alimentícios.

IFAM, 2015.PESSATI, M. L. Inventário da geração de resíduos de pescados em Santa Catarina e potenciais aplicações, 2004. REILLY, C. Too much of a good thing? The problem of traceelement fortification of foods.Trends in Food Science \& Technology, v. 7, p.139-142, 1996.

REIS, T.A. Caracterizacao de macarrão massa seca enriquecido com farinha de polpa de pescado, Lavras-MG, 2013.

SIDWELL, V. D.; HAMMERLE, O. A. Changes in Physical and Sensory Characteristics of Doughs and of Bread
Containing Various Amounts of Fish Protein Concentrate and Lysine. Cereal Chemistry, v. 47, p. 739-745, 1970.

SILVA, N., JUNQUEIRA, V. C. A., SILVEIRA, N. F. A. Manual de Métodos de Análise Microbiológica de Alimentos. São Paulo: Livraria Valera, 1997.SILVA, NEUSELY DA,et al. Manual de Métodos de Análise Microbiológica de Alimentos e Água - São Paulo: Editora Varela, 2010.

TAVARES, T. S; BASTOS, S.C; PIMENTA, M.E.S.G; PINHEIRO, A.C.M; FABRICIO, L.P.F; LEAL, R.S. Perfil sensorial de pães de forma enriquecido com farinha de matrinxã (Brycon Lundii) . UFLA, 2010.

TEIXEIRA, E., MEINERT, E. M., BARBETTA, P. A. Análise sensorial de alimentos. Florianópolis: Editora da UFSC, 1987. 